\title{
The Influence of Gayatri Mantra and Emotional Freedom Technique on Quality of Life of Post-Stroke Patients
}

This article was published in the following Dove Press journal: Journal of Multidisciplinary Healthcare

\author{
Ni Luh Putu Thrisna Dewi $\mathbb{D}^{\prime}$ \\ Muhamad Thohar Arifin (D) ${ }^{2}$ \\ Suhartini Ismail $\mathbb{D}^{3}$ \\ 'Nursing Program, STIKes Wira Medika \\ Bali, Denpasar, Bali, Indonesia; \\ ${ }^{2}$ Department of Neurosurgery, Faculty of \\ Medicine, Diponegoro University, \\ Semarang, Indonesia; ${ }^{3}$ Emergency and \\ Critical Care Division, Department of \\ Nursing, Faculty of Medicine, Diponegoro \\ University, Semarang, Indonesia
}

Correspondence: Muhamad Thohar Arifin Departement of Neurosurgery, Faculty of Medicine, Diponegoro University, Semarang, Indonesia Email thohar@fk.undip.ac.id
Purpose: The quality of life in stroke patients is vital for survival. Nowadays, studies that show a decrease in quality of life in post-stroke patients are increasing. Various nonpharmacological modalities were explored in the past to improve rehabilitation. However, the study about the effects of religious mantra and its combination with the modern technique was lacking. Therefore, this study aimed to analyse the effects of Gayatri Mantra and Emotional Freedom Technique (EFT) on quality of life (QOL) of post-stroke patients.

Methods: A quasi-experimental with pretest and posttest with the control group design was conducted. Forty-six post-stroke subjects with reduced quality of life based on Stroke Specific Quality of Life were consecutively recruited and divided into controls and intervention groups. The intervention group received additional treatment with Gayatri Mantra and EFT. In contrast, the control group attends and adheres only to the standard hospital rehabilitation program.

Results: All indicators and the overall score of QOL in the intervention group showed significant improvement after treatment $(p<0.05)$ compared with no improvement in the control group. Overall, a higher QOL score was observed in the intervention group at the end of the study. Mann-Whitney test shows significant differences between the final QOL score in intervention and control groups $(p<0.001)$.

Conclusion: Gayatri Mantra and EFT are significantly increasing the quality of life of poststroke patients.

Keywords: religion, quality of life, stroke

\section{Introduction}

Stroke incidence continues to increase both in developed and developing countries. The World Health Organization (WHO) in 2015 states that 15 million people are affected by stroke each year and ranked second as the leading cause of death after ischemic heart disease. ${ }^{1}$ According to the Indonesian Stroke Foundation, Indonesia has the highest number of stroke patients and ranks first in Asia. ${ }^{2}$

Stroke accounted for $28.5 \%$ of death in the urban area and was considered as the leading cause of death accordingly. Stroke patients face a variety of physical, psychological and emotional problems that affect their ability to perform daily life activities (ADL). ${ }^{3}$ Besides, stroke is the number one cause of permanent disability in the world. Approximately $56.5 \%$ had either partial or complete paralysis, and only $15 \%$ were completely recovered. ${ }^{4}$ Stroke also causes disturbances in the control of movement, disturbances in emotion and sensory perception, including 


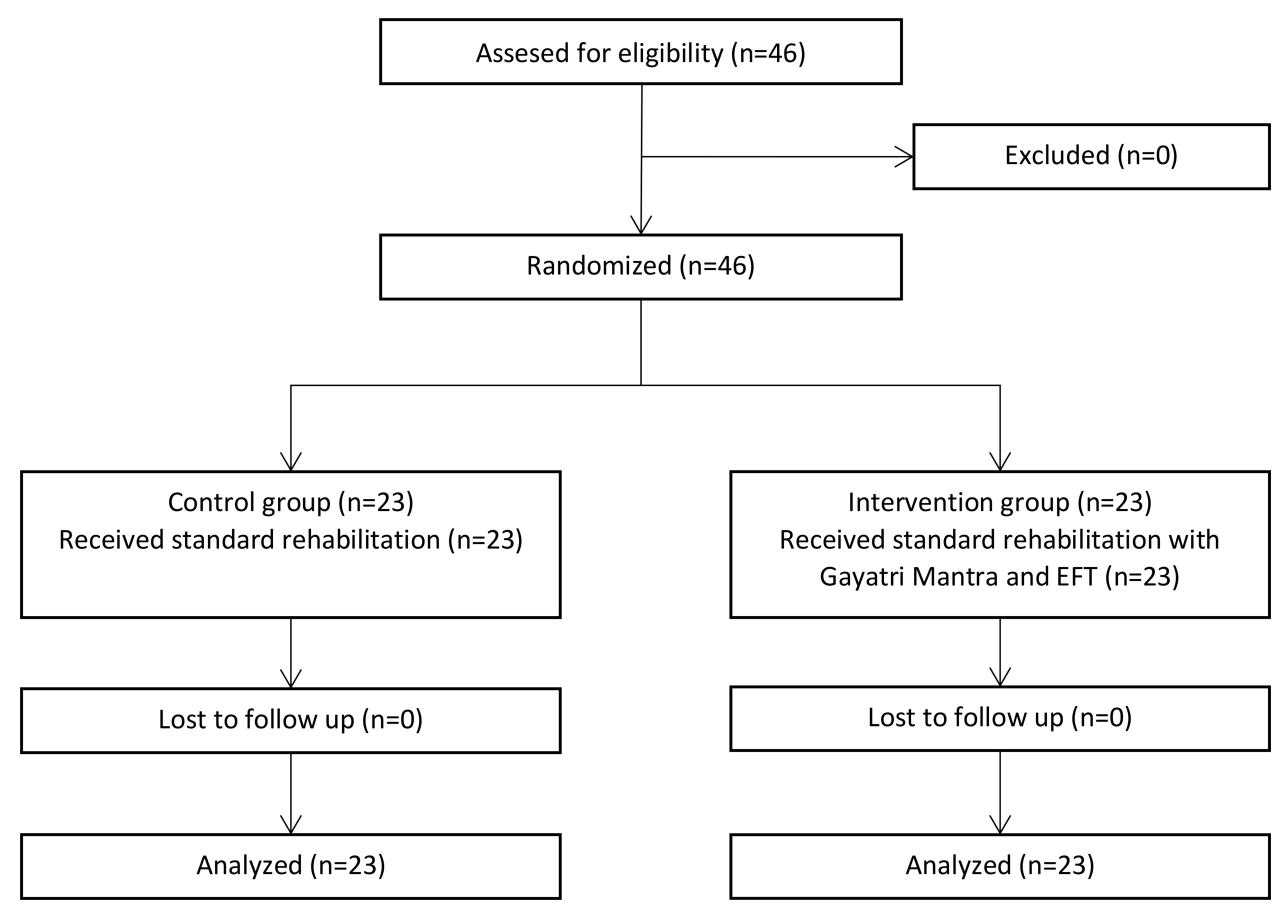

Figure I Flow of patients through the study for Gayatri Mantra and Emotional Freedom Technique (EFT).

pain, impairment in memory, communication and thinking process as well as fatigue. All of these complications lead to decreased quality of life. ${ }^{3,5,6}$

The quality of life in stroke patients is vital for survival. ${ }^{7}$ Nowadays, studies that show a decrease in quality of life in post-stroke patients are increasing. In Turkey, by $40 \%,{ }^{3}$ in Iran, $70 \%,{ }^{8}$ in Canada, $72.5 \%,{ }^{9}$ and Indonesia $72 \%{ }^{10}$ Patients who had a low Quality of life after a stroke were associated with a decreased ADL function. ${ }^{8,9}$ The continually decreasing quality of life affects the various aspects of post-stroke life, including physical and psychological well-being, social and economic welfare as well as its role activities. Ultimately it will impair the rehabilitation process as well as overall health and can even end in death. ${ }^{11}$

Quality of life refers to a conceptual measurement that includes the welfare, quality of survival as well as the extent to which a person can perform activities independently in chronic diseased conditions. Quality of life is also a parameter for assessing the efficacy of therapy given to patients. ${ }^{12}$ Therefore, nurse concern regarding patients quality of life becomes an integral part of nursing care to maximise the treatment outcome. ${ }^{13,14}$

Emotional freedom techniques (EFT) have been studied as an intervention for a variety of psychological conditions, including phobias, depression, anxiety, and posttraumatic stress disorder (PTSD). A theoretical framework for EFT physiological mechanisms of action has emerged. A series of review papers have elucidated the neuronal, genetic, neurotransmitter, and hormonal pathways that may be engaged when EFT alleviates psychological stress. ${ }^{15,16}$ EFT has previously been shown to produce substantial improvements in psychological symptoms, as well as the regulation of EEG stress marker. ${ }^{17,18}$

Various non-pharmacological modality from a traditional supplement to cognitive methods was explored in the past to improve rehabilitation. However, the study about the effects of religious mantra and its combination with the modern technique was lacking.

The current study tested the hypothesis that Gayatri Mantra and Emotional Freedom Technique produce similar effects on the quality of life of post-stroke patients.

\section{Methods}

This study was quasi-experimental, pre-post test with a control group design. ${ }^{19}$ Consecutive sampling was used in this study to recruit 46 post-stroke patients admitted to Bangli General Hospital and Wangaya General Hospital, Bali, Indonesia, from March to May 2018 (Figure 1). Inclusion criteria were ischemic stroke patients in postacute phase ( $>48 \mathrm{hrs}$ ) with moderate dependence, fully conscious (compos mentis) with proper mental function 
Table I Baseline Characteristics of Subjects

\begin{tabular}{|c|c|c|c|c|}
\hline \multicolumn{2}{|c|}{ Baseline Characteristics } & \multirow{3}{*}{$\begin{array}{l}\text { Intervention Group } \\
\text { n (\%) } \\
13(56.5) \\
10(43.5)\end{array}$} & \multirow{3}{*}{$\begin{array}{l}\text { Control Group } \\
\text { n (\%) } \\
9(39.1) \\
14(60.9)\end{array}$} & \multirow{3}{*}{$\begin{array}{l}p \text {-value } \\
0.230\end{array}$} \\
\hline & & & & \\
\hline Age & $\begin{array}{l}50-55 \\
56-60\end{array}$ & & & \\
\hline Gender & $\begin{array}{l}\text { Male } \\
\text { Female }\end{array}$ & $\begin{array}{l}14(60.9) \\
9(39.1)\end{array}$ & $\begin{array}{l}\text { I5 (65.2) } \\
8(34.8)\end{array}$ & 0.760 \\
\hline Education & $\begin{array}{l}\text { Elementary } \\
\text { Junior High School } \\
\text { Senior High School } \\
\text { University }\end{array}$ & $\begin{array}{l}6(26.1) \\
5(21.7) \\
7(30.4) \\
5(21.7)\end{array}$ & $\begin{array}{l}7(30.4) \\
6(26.1) \\
5(21.7) \\
I I(2 I .7)\end{array}$ & 0.910 \\
\hline Occupation & $\begin{array}{l}\text { Self-employed } \\
\text { Public Servant }\end{array}$ & $\begin{array}{l}13(56.5) \\
10(43.5)\end{array}$ & $\begin{array}{l}\text { II (47.8) } \\
\text { I2 (52.2) }\end{array}$ & 0.550 \\
\hline Period of Disease & $\begin{array}{l}<\text { I year } \\
\geq \text { I year }\end{array}$ & $\begin{array}{l}\text { II (47.8) } \\
\text { I2 (52.2) }\end{array}$ & $\begin{array}{l}10(43.5) \\
13(56.5)\end{array}$ & 0.760 \\
\hline Motoric Impairment & $\begin{array}{l}\text { Left Hemiparesis } \\
\text { Right Hemiparesis }\end{array}$ & $\begin{array}{l}13(56.5) \\
10(43.5)\end{array}$ & $\begin{array}{l}10(43.5) \\
13(56.5)\end{array}$ & 0.370 \\
\hline
\end{tabular}

(assessed with Mini-mental state examination (MMSE) score according to education level), able to communicate verbally, were adherents to Hinduism and willing to involved in the research. Subjective units distress scale (SUDS) questionnaire is used to evaluate the emotion of subjects before Gayatri manta and EFT intervention in each session. Exclusion criteria were patients in critical condition and patients who refuse to continue Gayatri Mantra and EFT therapy for 1 week.

Quality of life post-stroke patient was measured preand post-intervention using stroke-specific quality of life (SS-QOL). The SS-QoL is an instrument specifically used to assess health-related QoL among individuals who experienced stroke. The SS-QoL has been validated and transculturally adapted for Indonesian; it has 49 items in 12 domains, varying from 49 to 245 points, with responses varying from 1 to 5 points. Higher values indicate better health-related QoL. All questionnaires were performed face-to-face with the patient in the medical consultation obeying the specific guidelines in the application of each one.

The intervention group was given additional treatment with Gayatri Mantra and Emotional Freedom Technique (EFT) and performed in 7 consecutive days guided by the researchers once a day. While the control group attends and adhere only to the standard hospital rehabilitation program. The research intended to show the difference in
Quality of Life (QoL) score of post-stroke patients between the intervention and control group. ${ }^{20}$ The subjects were divided equally into intervention and control groups. Baseline characteristics assessed were age, sex, education, occupation, duration of illness, and the hemiparetic side.

Descriptive and inferential statistics were used with Statistical Package for the Social Sciences software. SSQoL values were compared with nominal social and clinical characteristics using the Mann-Whitney test to compare variables with two categories (intervention and control groups). This research has been ethically reviewed and approved by the Institutional Review Board of Faculty of Medicine Diponegoro University, Semarang, Indonesia. (Ethical Clearance Number:79/EC/FK-RSDK/II/2018) We conduct our studies in compliance with recognized international standards, hospital standard and the principles of the Declaration of Helsinki. Prior written informed consent was obtained from all patients for being included in this study.

\section{Results}

Descriptive data of the subject characteristic are presented in Table 1. T Regarding the sociodemographic and clinical characteristics of patients with stroke age ranged 50-60 years old, with most of the intervention groups aged 50-55 years old $(56.5 \%)$ while the control group was 56-60 years old $(60.9 \%)$. Based on the gender, stroke mostly occurred 
in men; it accounts for $60.9 \%$ of the intervention group and $65.2 \%$ control groups. The level of education in the intervention group mostly graduated from senior high school $(30.4 \%)$. Employment status in the intervention group was dominated by self-employed with 13 respondents $(56.5 \%)$, while in the control group dominated by civil servants $(52.2 \%)$. The percentage of patients with duration of illness for 1 year or more in the intervention group was $52.2 \%$. In contrast, the control group was 56.5\%. The dominant hemiparetic side experienced by the patients in the intervention group was the left side (56.5\%), while the control group on the right side $(56.5 \%)$. The distribution of each characteristics variables was compared and showed no statistically significant difference between control and intervention group ( $p>0.05$ ).

All indicators of quality of life showed significant improvement at the end of the study period $(p<0.05)$, as shown in Table 2 . The quality of life scores in the intervention group before and after given treatment with Gayatri Mantra \& EFT showed significant improvement $(p<0.001)$. All quality of life indicators did not increase significantly in the control group, with $p>0.05$ for all the twelve indicators and overall quality of life score.

This study achieved the power and effect size at 0.80 and 0.50 consecutively. It shows that the intervention which is given to the post-stroke patients is given effect to increase the patient's QOL.

Overall, a higher quality of life score was observed in the intervention group receiving Gayatri Mantra \& EFT treatment compared with the non-treated control group. Mann-Whitney test shows significant differences between the quality of life score in intervention and control groups $(p<0.001)$ (see Table 3).

\section{Discussion}

Quality of life in stroke patients includes four domains that are related to each other. Those are physical, psychological, social and environmental domains. Research showed that one domain affects the other domain so that the assessment of the quality of life is very complicated. Consequently, it cannot be separated between one domain with other domains. In this study, quality of life was measured using Stroke Specific Quality of Life (SSQOL). This instrument has been tested valid and reliable. The instrument consists of 49 question items to measure all domains of quality of life.

The physical health domain of this research consists of seven aspects. The first aspect is to cope with pain or discomfort. Pain and discomfort are related to the quality of life because it can describe the patient physical-sensations. The example was a sense of tingling or difficulty to stand or walk. In most cases, stroke patients included in this study complain about pain, so it is considered as one of the triggers of the decline in quality of life. ${ }^{21}$ The second aspect is the energy and fatigue felt by the patients both in the intervention group or the control group. This aspect illustrates the decreased perceived energy, enthusiasm and endurance the patient has for their daily activities after stroke. Similar things expressed by Barbour that fatigue can affect the recovery process in stroke patients. Fatigue can be caused by several factors, including lesions experienced during the stroke, long periods of hospitalisation, sleep disturbances and when patients feel bored following the rehabilitation process. These problems required complex treatment. If left untreated, it can deteriorate the quality of life. $^{22}$

The third aspect is sleep and rest, as both can affect the quality of life. ${ }^{23}$ The fourth aspect is mobility; the side of weakness depends on the part of the brain affected by stroke. The perceived weakness of the patient will affect the body energy and might raise the sensation of pain felt by the patient. ${ }^{24}$ The fifth aspect is the ability to perform daily activities; this aspect focuses on the ability of respondents to carry out necessary activities such as for bathing or eating and drinking. In this study, the respondents still need the help of others.

The sixth aspect is the dependence of substance or drugs. All of the respondents, both the intervention group and the control group still receive medication and standard treatment from the hospital. Only the intervention group get additional therapy with Gayatri Mantra and Emotional Freedom Technique which can support physical and psychological welfare of stroke patient.

The last aspect of the physical domain is work capacity. The respondents stated that residual symptoms decreased the quantity of work either in the office or as an entrepreneur. Optimal rehabilitation is needed so that the stroke patient can independently meet their basic needs and improve their work capacity. The same is revealed by Baldwin (2015) that substantial rehabilitation is carried out after stroke because $20 \%$ of stroke patients are currently at a productive age who are still active at work. Persistence to work on post-stroke period can indicate an improvement in the quality of life. ${ }^{24}$

The psychological domain of this study consists of six aspects. The first aspect is positive feelings; in the SS- 


\begin{tabular}{|c|c|c|c|c|c|c|c|c|c|c|c|c|c|c|c|}
\hline & 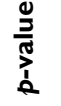 & & $\begin{array}{l}\sigma \\
\alpha \\
\dot{\alpha} \\
\wedge\end{array}$ & $\frac{0}{m}$ & $\begin{array}{l}\alpha \\
\sigma \\
0 \\
\wedge\end{array}$ & $\begin{array}{c}\frac{0}{m} \\
0\end{array}$ & $\begin{array}{l}\alpha \\
\sigma \\
\dot{\Lambda} \\
\Lambda\end{array}$ & $\begin{array}{l}\alpha \\
\alpha \\
\alpha \\
\hat{\Lambda}\end{array}$ & $\frac{o}{m}$ & $\frac{\circ}{m}$ & ণ্ণি & $\begin{array}{l}\text { बे } \\
\text { ○े } \\
\text { रे }\end{array}$ & $\frac{\infty}{0}$ & 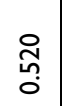 & $\frac{q}{0}$ \\
\hline & & 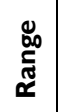 & $\frac{\simeq}{\underline{d}}$ & $\frac{m}{\underline{d}}$ & $\begin{array}{l}\frac{\infty}{1} \\
\simeq\end{array}$ & $\begin{array}{l}\frac{\infty}{\perp} \\
\simeq\end{array}$ & $\frac{\pi}{1}$ & $\frac{\underline{n}}{\frac{1}{d}}$ & $\frac{m}{\alpha}$ & $\frac{m}{\alpha}$ & $\frac{n}{\alpha}$ & $\begin{array}{l}\frac{m}{1} \\
\underline{o}\end{array}$ & $\frac{m}{\underline{d}}$ & $\frac{m}{\underline{d}}$ & $\begin{array}{l}\bar{\sigma} \\
\bar{b} \\
\underline{\underline{0}}\end{array}$ \\
\hline & 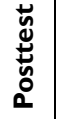 & 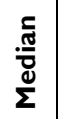 & $=$ & $\simeq$ & $\underline{\underline{n}}$ & \pm & $=$ & $\simeq$ & $=$ & $=$ & $\simeq$ & $=$ & $=$ & $=$ & $\stackrel{\mathcal{I}}{ }$ \\
\hline & & 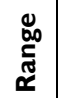 & $\frac{1}{\underline{d}}$ & $\frac{m}{\bar{d}}$ & $\begin{array}{l}\frac{\infty}{\Lambda} \\
\simeq\end{array}$ & $\stackrel{\infty}{\underline{\Lambda}}$ & $\frac{ \pm}{d}$ & $\frac{\sigma}{d}$ & $\frac{m}{\alpha}$ & $\frac{m}{d}$ & $\frac{n}{1}$ & $\frac{m}{\alpha}$ & $\frac{m}{\alpha}$ & $\frac{m}{d}$ & $\begin{array}{l}\overline{\underline{0}} \\
\underline{\omega} \\
\underline{m}\end{array}$ \\
\hline 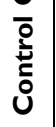 & 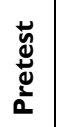 & 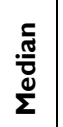 & $=$ & $\simeq$ & $\underline{\underline{n}}$ & \pm & $=$ & $\underline{m}$ & $=$ & $=$ & $\simeq$ & $\simeq$ & $=$ & $=$ & $\underline{\mathcal{F}}$ \\
\hline & 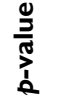 & & $\frac{0}{0}$ & $\begin{array}{l}\stackrel{0}{0} \\
\stackrel{0}{0}\end{array}$ & ¿̊. & $\begin{array}{l}\overline{8} \\
\text { v }\end{array}$ & ্ֻ. & $\begin{array}{l}\overline{8} \\
\text { v }\end{array}$ & $\stackrel{\circ}{\circ}$ & 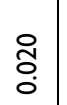 & $\frac{0}{0}$ & $\begin{array}{l}\stackrel{0}{0} \\
\stackrel{0}{0}\end{array}$ & ֻ̊. & $\begin{array}{l}\overline{8} \\
\overline{0} \\
\mathrm{v}\end{array}$ & $\begin{array}{l}\overline{8} \\
\dot{0} \\
\mathrm{v}\end{array}$ \\
\hline & & 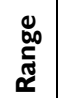 & $\frac{n}{\alpha}$ & $\frac{\underline{n}}{\underline{d}}$ & $\underset{\tilde{I}}{\underline{I}}$ & $\begin{array}{l}\frac{\infty}{1} \\
\underline{I}\end{array}$ & $\frac{\Delta}{d}$ & $\frac{\infty}{\underline{1}}$ & $\frac{\underline{n}}{1}$ & $\frac{\underline{n}}{1}$ & $\frac{0}{1}$ & $\frac{\underline{n}}{\underline{1}}$ & $\frac{\overline{1}}{0}$ & $\begin{array}{l}0 \\
0 \\
0\end{array}$ & $\begin{array}{l}\frac{\hat{\kappa}}{\hat{T}} \\
\frac{\hat{\alpha}}{\underline{y}}\end{array}$ \\
\hline & 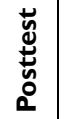 & 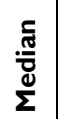 & $=$ & $=$ & $\underline{-}$ & $\underline{\underline{n}}$ & $\simeq$ & \pm & $\simeq$ & $\simeq$ & \pm & $\simeq$ & $\simeq$ & $\simeq$ & 드 \\
\hline$\stackrel{0}{\circ}$ & & 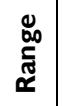 & $\frac{\pi}{\alpha}$ & $\frac{n}{\infty}$ & $\begin{array}{l}\tilde{N} \\
\text { ô }\end{array}$ & $\overline{\bar{d}}$ & $\frac{ \pm}{1}$ & $\frac{\underline{n}}{\underline{d}}$ & $\frac{\underline{n}}{\underline{d}}$ & $\frac{\underline{n}}{\underline{d}}$ & $\frac{0}{1}$ & $\frac{\underline{L}}{\underline{d}}$ & $\overline{\bar{d}}$ & $\frac{n}{d}$ & $\begin{array}{l}\mathbf{0} \\
\frac{1}{d} \\
\underline{I}\end{array}$ \\
\hline 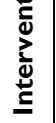 & 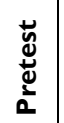 & 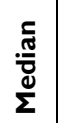 & $=$ & $=$ & $\underline{\underline{n}}$ & $\underline{m}$ & $=$ & $\underline{m}$ & $\simeq$ & $\simeq$ & $\underline{m}$ & $\simeq$ & $\simeq$ & $=$ & 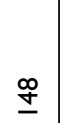 \\
\hline 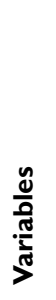 & & & 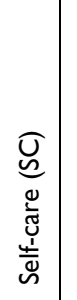 & $\begin{array}{l}\sum \\
\bar{c} \\
\frac{o}{y}\end{array}$ & 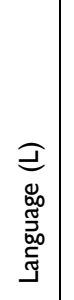 & 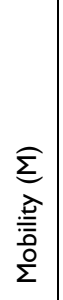 & 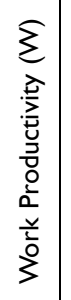 & 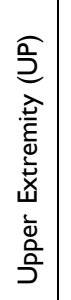 & 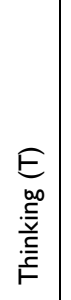 & 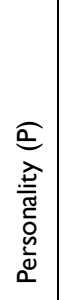 & $\begin{array}{l}\widehat{\Sigma} \\
0 \\
\delta \\
\Sigma\end{array}$ & 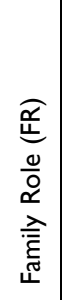 & 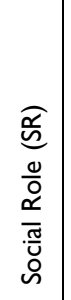 & $\begin{array}{l}\widetilde{U} \\
\grave{b} \\
\underline{\omega} \\
\tilde{w}\end{array}$ & 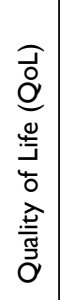 \\
\hline
\end{tabular}


Table 3 The Difference in Quality of Life Between Groups

\begin{tabular}{|l|l|l|l|l|}
\hline Groups & Mean Rank & Sum of Rank & Z score & -value \\
\hline Intervention Group & 33.11 & 761.50 & -5.27 & $<0.001$ \\
Control Group & 13.89 & 319.50 & & \\
\hline
\end{tabular}

QOL questionnaire, there is one question that relates the respondent's feelings to what is felt right now after a stroke. Most patients said they felt worse because of their future perspective about what currently experienced was related to the quality of lives. The second aspect includes memory, learning, thinking, and concentration. In this study, all the respondents were recruited when the MMSE score met the requirement. MMSE is a way to assess the patient's cognitive level, and the results were following the education level of each respondent. The third aspect is self-esteem. After being treated, the respondent of the intervention group felt better. The results of this study were in agreement with research conducted by Hama et al (2011) which states that if an inadequate psychological response is left untreated, it will slow the patient's physical improvement. ${ }^{25}$

The next aspect is the body image or body appearance. During the treatment process, the respondent in the intervention group began to improve. Although it still might be supported when going to the toilet, the control group was still having difficulty walking, because it had not been able to maintain balance when standing and depend on the caregivers. The fifth aspect is the negative feelings of despair, guilt and anxiety experienced by the respondent when they felt the negative impact affects their daily activities. The last aspect is the spiritual/religion/beliefs of the respondents. In this study, respondents adhered to Hinduism. Researchers provide treatment to the intervention group by including the beliefs that the patient has. In addition to the successful approach, respondents also have faith in the Gayatri Mantra and EFT, so the intervention was conducted optimally. It is evident from the results that showed a significant change in the quality of life indicators towards improvement in all respondents of the intervention group. This study is in line with research conducted by approaching patients using the Emotional Freedom Technique intervention on respondents to improve sleep quality and quality of life of patients on post-operative recovery. $^{26}$

The third domain of quality of life is a social relationship, includes three aspects, ie, personal relationship, social support, and sexual activity assessed through SSQOL questionnaire used in this research. One of the questions on SS-QOL assessed the extent to which patients can socialise in the home or community after a stroke. The results showed that respondents experienced a decrease in social relationships because most patients choose to have a rest immediately after work due to the fatigue they experienced. The results of this study were in line with research conducted by Cacioppo. It showed social relationships in chronic diseases could be decreased due to the disturbance of mental function, and physical welfare that causes a range of movements to become more limited, which ultimately decreased the quality of life. ${ }^{27}$

The environment domain has eight aspects; the first is freedom, security, and physical safety. In the intervention and the control group, the respondents felt that their families helped them when hospitalised because of their physical limitation. The second aspect is the environment around the house. Respondents feel more comfortable living at home, and they went out only for work. Moreover, they less likely to hang out with neighbours after they experienced the illness.

The third aspect is the source of funds. All respondents in this study using health insurance, therefore only a few drugs that must be purchased. Limited conditions make the respondent unable to work optimally, and the medical expenses required during the recovery process also become one of the negative stressors that decrease the quality of life. The same results from this study were similar to Lowres study. They conduct research in Australia on cost savings in the stroke patient at the recovery stage. In his study, stroke patients who experience clinical deterioration would extend the treatment period and require more expense. It is not only a problem for the patient but also the patient's own family. ${ }^{28}$

The fourth aspect is the health and social security, including its access and quality. In this case, the respondents from the intervention or control group preferred to seek modern health care rather than to alternative medicine. The fifth aspect, all respondents have a right to get precise information about their condition. The information 
needs have relevance to the quality of one's life. The sixth aspect is participation and opportunities for recreation/ relaxing with family. The seventh aspect is the physical environment. During the study, the hospital environment also affects the patient recovery process. The last aspect is that respondents' transportation, in general needs the help of others. Padilla \& Grant model states that quality of life is a multidimensional concept. It consists of the psychological dimensions of well-being, body image concerns, social concerns, physical well-being, and response to diagnosis and treatment actions. ${ }^{29}$

Different cultures will give a different perspective for the patients to accept their condition and underwent treatment during the recovery process. Professional and standardised nursing services should be emphasised to prevent additional residual symptoms and seek to improve the quality of life of post-stroke patients. Patient confidence should be used to drive the healing process. Leininger assumes that care with transcultural nursing can provide significantly better outcomes. ${ }^{30}$ Leininger theory is evident in this study, the intervention provided by researchers namely Emotional Freedom Technique with Gayatri Mantra which is one of the beliefs of Hinduism religion, gives a positive influence towards the improvement of the quality of life post-stroke patients. We established a new approach to improve the quality of life of patients with stroke by using religious mantra and its combination with the modern technique in the present study. This is an inexpensive yet effective one worth trying. However, there are a few limitations to this study. The first limitation concerns the sample size and participants' characteristics. We were not able to control for age, sex, onset time, lesion side, or severity of cognitive impairment. The second limitation is the short time between treatment and follow-up.

\section{Conclusion}

Stroke is a chronic disease with significant sequelae such as pain, paresthesia, weakness, anxiety, depression, and reduced quality of life. These physical and psychological problems should be treated by applying a holistic perspective, including pharmacological and non-pharmacological approach. Gayatri Mantra and Emotional Freedom Technique (EFT) is a combination of non-pharmacological intervention using the flow of energy in the patient's body to optimise the healing process in the recovery phase suitable for Hindu people.

\section{Acknowledgments}

This paper is part of the thesis that deposit in the university repository. ${ }^{31}$ We would like to thank STIKes Wira Medika Bali, Bangli General Hospital, Wangaya General Hospital, Denpasar and all respondents of this study.

\section{Disclosure}

All authors declare no conflict of interest regarding this work and the publication of this article.

\section{References}

1. Feigin VL, Forouzanfar MH, Krishnamurthi R, et al. Global and regional burden of stroke during 1990-2010: findings from the global burden of disease study 2010. Lancet. 2014;383(9913):245-255. doi:10.1016/S0140-6736(13)61953-4

2. Pendlebury ST, Rothwell PM. Prevalence, incidence, and factors associated with pre-stroke and post-stroke dementia: a systematic review and meta-analysis. Lancet Neurol. 2009;8(11):1006-1018. doi:10.1016/S1474-4422(09)70236-4

3. Haghgoo HA, Pazuki ES, Hosseini AS, Rassafiani M. Depression, activities of daily living and quality of life in patients with stroke. $J$ Neurol Sci. 2013;328(12):87-91. doi:10.1016/j.jns.2013.02.027

4. Ovbiagele B, Bath PM, Cotton D, Vinisko R, Diener HC. Obesity and recurrent vascular risk after a recent ischemic stroke. Stroke. 2011;42 (12):3397-3402. doi:10.1161/STROKEAHA.111.624957

5. Chuluunbaatar E, Chou Y-J PC. Quality of life of stroke survivors and their informal caregivers: a prospective study. Disabil Health $J$. 2016;9(2):306-312. doi:10.1016/j.dhjo.2015.10.007

6. Ponchel A, Bombois S, Bordet R, Hénon H. Factors associated with poststroke fatigue: a systematic review. Stroke Res Treat. 2015;2015:347920.

7. Laurent K, De Sèze M-P, Delleci C, et al. Assessment of quality of life in stroke patients with hemiplegia. Ann Phys Rehabil Med. 2011;54(6):376-390. doi:10.1016/j.rehab.2011.06.002

8. Kelly A, Rush J, Shafonsky E, et al. Detecting short-term change and variation in health-related quality of life: within- and between-person factor structure of the SF-36 health survey. Health Qual Life Outcomes. 2015;13:199. doi:10.1186/s12955-015-0395-1

9. Gunaydin R, Goksel A, Kaya T, Ulutas O. Determinants of quality of life $(\mathrm{QoL})$ in elderly stroke patients: a short-term follow-up study. Arch Gerontol Geriatr. 2011;53:19-23. doi:10.1016/j. archger.2010.06.004

10. Norris M, Allotey P, Barrett G. "It burdens me": the impact of stroke in central Aceh, Indonesia. Social Heal Illn. 2012;34(6):826-840. doi:10.1111/j.1467-9566.2011.01431.x

11. Lerdal A, Gay CL. Acute-phase fatigue predicts limitations with activities of daily living 18 months after first-ever stroke. $J$ Stroke Cerebrovasc Dis. 2017;26(3):523-531. 1. doi:10.1016/j. jstrokecerebrovasdis.2016.11.130

12. Embuldeniya G, Veinot P, Bell E, et al. The experience and impact of chronic disease peer support interventions: A qualitative synthesis. Patient Educ Couns. 2013;92(1):3-12. doi:10.1016/j.pec.2013.02.002

13. Bakas T, McLennon SM, Carpenter JS, et al. Systematic review of health-related quality of life models. Health Qual Life Outcomes. 2012;10(1):134. doi:10.1186/1477-7525-10-134

14. Opara JA, Jaracz K. Quality of life of post-stroke patients and their caregivers. $J$ Med Life. 2010;3(3):216-220.

15. Feinstein D. Rapid treatment of PTSD: why psychological exposure with acupoint tapping may be effective. Psychother Theory Res Pract Train. 2010;47:385-402. doi:10.1037/a0021171 
16. Feinstein D, Church D. Modulating gene expression through psychotherapy: the contribution of non-invasive somatic interventions. Rev Gen Psychol. 2010;14:283-295. doi:10.1037/a0021252

17. Gallo F. Energy psychology in rehabilitation: origins, applications, and theory. Energy Psychol Theory Res Treat. 2009;1(5772).

18. Church D, Feinstein D. The manual stimulation of acupuncture points in the treatment of post-traumatic stress disorder: a review of clinical emotional freedom techniques. Med Acupunct. 2017;29(4):194-205. doi:10.1089/acu.2017.1213

19. Kontopantelis E, Doran T, Springate DA, Buchan I, Reeves D. Regression based quasi-experimental approach when randomisation is not an option: interrupted time series analysis. BMJ. 2015;350:1-4. doi:10.1136/bmj.h2750

20. Christensen LB, Johnson RB, Turner LA. Research methods, design, and analysis. Arastirma Yöntemleri Desen Ve Anal. 2014;217-249.

21. Aprile I, Briani C, Pazzaglia C, et al. Pain in stroke patients: characteristics and impact on the rehabilitation treatment. A multicenter cross-sectional study. Eur J Phys Rehabil Med. 2015;51 (6):725-736.

22. Barbour VL, Mead GE. Fatigue after stroke: the patient's perspective. Stroke Res Treat. 2012;2012:863031. doi:10.1155/2012/863031

23. Eilertsen G, Ormstad H, Kirkevold M, Mengshoel AM, Soderberg S, Olsson M. Similarities and differences in the experience of fatigue among people living with fibromyalgia, multiple sclerosis, ankylosing spondylitis and stroke. J Clin Nurs. 2015;24(1314):2023-2034. doi:10.1111/jocn. 12774
24. Baldwin C, Brusco NK. The effect of vocational rehabilitation on return-to-work rates post-stroke: a systematic review. Top Stroke Rehabil. 2011;18(5):562-572. doi:10.1310/tsr1805-562

25. Hama S, Yamashita H, Yamawaki S, Kurisu K. Post-stroke depression and apathy: interactions between functional recovery, lesion location, and emotional response. Psychogeriatrics. 2011;11(1):6876. doi:10.1111/j.1479-8301.2011.00358.x

26. Church D. Clinical EFT as an evidence-based practice for the treatment of psychological and physiological conditions. Psychology. 2013;04(08):645-654. doi:10.4236/psych.2013.48092

27. Cacioppo JT, Cacioppo S. Social relationships and health: the toxic effects of perceived social isolation. Soc Personal Psychol Compass. 2014;8(2):58-72. doi:10.1111/spc3.12087

28. Lowres N, Neubeck L, Salkeld G, et al. Feasibility and cost-effectiveness of stroke prevention through community screening for atrial fibrillation using iPhone ECG in pharmacies. Thromb Haemost. 2014;111(06):1167-1176. doi:10.1160/TH14-03-0231

29. King CR, Hinds PS. Quality of Life: From Nursing and Patient Perspectives: Theory, Research, Practice. 3rd ed. Jones and Bartlett Publishers; 2003.

30. Marilyn E, Parker MCS. Nursing Theories \& Nursing Practice. 3rd ed F. A. Davis Company Publishers 2010.

31. Dewi N, Arifin M, Suhartini S (2018) The Effect of Gayatri Mantra and Emotional Freedom Technique (Eft) on the Quality of Life of Post-Stroke Patients. Masters thesis. Diponegoro University. Retrieved from http:// eprints.undip.ac.id/62849/. Accessed August 21, 2020.
Journal of Multidisciplinary Healthcare

\section{Publish your work in this journal}

The Journal of Multidisciplinary Healthcare is an international, peerreviewed open-access journal that aims to represent and publish research in healthcare areas delivered by practitioners of different disciplines. This includes studies and reviews conducted by multidisciplinary teams as well as research which evaluates the results or conduct of such teams or healthcare processes in general. The journal covers a very wide range of areas and welcomes submissions from practitioners at all levels, from all over the world. The manuscript management system is completely online and includes a very quick and fair peer-review system. Visit http://www.dovepress.com/testimonials. php to read real quotes from published authors. 